\title{
URBAN SHRINKAGE AND SOCIO-ECONOMIC SEGREGATION IN MEDIUM-SIZED CITIES: THE CASE OF SCHWERIN (GERMANY)
}

\author{
DAvid Huntington @ \\ Department of Economic Geography, Faculty of Human Geography and Planning, \\ Adam Mickiewicz University, Poznań, Poland
}

Manuscript received: June 7, 2021

Revised version: July 21, 2021

\begin{abstract}
Huntington D., 2021. Urban shrinkage and socio-economic segregation in medium-sized cities: The case of Schwerin (Germany). Quaestiones Geographicae 40(4), Bogucki Wydawnictwo Naukowe, Poznań, pp. 29-46. 6 figs, 1 table.

ABSTRACT: Although past studies have found that processes of urban shrinkage may act as a catalyst for socio-economic segregation, these relationships remain underexplored outside the context of large cities and capitals. Moreover, cities at lower-tiers of the urban hierarchy in post-socialist Europe have been doubly excluded from the critical discourse on the socio-spatial effects of shrinkage. Hence, this article examines how shrinkage affects socio-economic segregation in the medium-sized post-socialist city of Schwerin, employing segregation indices to assess levels of spatial unevenness and location quotients to map intra-urban patterns of vulnerable population groups over time. Results indicate processes of shrinkage may exacerbate socio-economic segregation in medium-sized cities and that the spatial heterogeneity of shrinkage intersects with uneven distributions of affluence and poverty. However, suggesting that legacies of state socialism shape contemporary socio-spatial change, segregation in Schwerin is strongly conditioned by its socialist-era housing estates, which are generally characterised by the highest rates of population decline, vacancy, and vulnerable groups.
\end{abstract}

KEYWORDS: urban shrinkage, socio-economic segregation, medium-sized cities, post-socialist cities, socio-spatial inequality

Corresponding author: David Huntington, Department of Economic Geography, Faculty of Human Geography and Planning, Adam Mickiewicz University, ul. B. Krygowskiego 10, 61-680 Poznań, Poland; e-mail: david.huntington@amu.edu.pl

\section{Introduction}

The development of European cities has become increasingly polarised in recent decades. While select cities have experienced population booms, labour market growth, and new forms of work, many others-above all small and medium-sized cities, but also numerous large cities and metropolitan areas-endured years of depopulation and job losses (Turok, Mykhnenko 2007; Wolff, Wiechmann 2018). Although the socio-spatial consequences of the phenomenon which has become known as 'urban shrinkage' are context-dependent and, therefore, may differ considerably between seemingly similar cities and regions, current theory and empirical evidence indicate that processes of demographic and economic decline generally precede shifts in the socio-spatial fabric of cities. For instance, population ageing and increasing concentrations of disadvantaged social groups are a common characteristic of so-called 'shrinking cities' due to their typical experiences with selective outmigration of younger, highly-educated, and middle- to 
upper-class segments of the population (Fol 2012; Großmann et al. 2013; Haase et al. 2016a, b). An increasing lack of job opportunities for those left behind on the one hand, and a scarcity of qualified working-age residents on the other may also place strains on the local economy. An unbalanced job market and rising unemployment may, in turn, damage a city's reputation and attractiveness to potential newcomers or investors. That the proliferation of vacant buildings and abandoned land tends to fuel outmigration as well as the stigmatisation of shrinking cities-or particular areas of cities-adds another layer to the socio-spatial challenges of urban shrinkage (Großmann et al. 2015). Ultimately, if left unchecked, continuous urban shrinkage and rising vacancies may spur a vicious cycle of socio-economic inequalities and spatial polarisation (Hoekstra et al. 2020).

Yet, although more than one-third of Europe's population reside in small and medium-sized cities with fewer than 100,000 residents (European Commission 2011), and despite the particular vulnerability of such cities to the negative effects of urban shrinkage given their alienation or resource-constraints (Wolff, Wiechmann 2018), existing investigations of how local experiences with shrinkage affect segregation are almost exclusively set in the context of capitals or large metropolitan areas (Großmann et al. 2015; Marcińczak et al. 2012; Petsimeris 1998; Valatka et al. 2016). The knowledge gap concerning the relationship between urban shrinkage and socio-economic segregation extends to lower-tier cities in the region of Central and Eastern Europe (CEE), the epicentre of urban shrinkage and location of some of the highest rates of population decline since the beginning of the post-socialist transition. Indeed, although numerous cities in CEE had already recorded population losses in the years leading up to the collapse of state socialism, the spread of suburbanisation, declining fertility rates, and persistent outmigration have since accelerated processes of urban shrinkage (Haase et al. 2016a, b; Stryjakiewicz, Jaroszewska 2016). In other words, our understanding of the relationship between shrinkage and segregation is not merely unclear, but decidedly biased towards the experiences of a narrow group of cities. The omission of small and medium-sized post-socialist cities from the shrinking cities literature is a practical problem for urban planning and policy-making because empirical verifications of how socio-spatial inequalities, such as socio-economic segregation, develop across different contexts are key to the development of evidence-based, place-sensitive responses.

Hence, the emphasis of this contribution is an empirical study of the socio-spatial restructuring of the medium-sized post-socialist city of Schwerin, Germany, paying particular attention to the explanatory power of processes of urban shrinkage on levels and patterns of socio-economic segregation over time. Schwerin experienced substantial population growth as a regional capital and prominent administrative centre prior to the Second World War, and afterwards as a centrally planned district capital of the German Democratic Republic (GDR). Since German reunification, Schwerin has faced nearly continuous population declines, decreasing from approximately 130,000 principal residents in 1988 to fewer than 96,000 as of 2019 . However, spatial patterns of depopulation in Schwerin have been far from evenly distributed; some districts are characterised by persistent outmigration and high vacancy rates while others struggle to meet housing demand. The following section summarises typical causes, consequences, and challenges of socio-economic segregation in the contemporary city. Subsequently, post-war paths of urban development and socio-spatial change in CEE are examined, focusing on the explanatory power of urban shrinkage on patterns of segregation. This is followed by a presentation of the study's methodology, an introduction to the case of Schwerin, and an examination of empirical results. Finally, key findings are summarised and discussed.

\section{Socio-economic segregation in the city}

The uneven spatial distribution of differing socio-economic population groups - a phenomenon known as socio-economic segregationappears to be on the rise in cities around the world (Bischoff, Reardon 2014; Marcińczak et al. 2016; van Ham et al. 2021). This has been attributed to broader processes of urban and suburban transformation; for instance, the revival of many inner-city areas, driven by the expansion 
of knowledge-based economic activities, capital investments in property development, new class dynamics and demographic transitions, has evidently impacted neighbourhood change and socio-spatial differentiation (Lees 2008). While inner-city revitalisation may initially result in social mixing and decreasing segregation, over time related processes of gentrification, such as rising property values and displacement, tend to exacerbate social homogenisation and segregation (van Gent, Hochstenbach 2020). Even in marginalised areas of cities with depressed housing markets, socio-spatial inequalities may be further aggravated by speculative business practices or exploitative landlords charging exorbitant rents (Desmond, Wilmers 2019).

Yet, contemporary segregation is also linked to macro-level structural changes in employment; for example, financial crises and a lack of secure, well-paying jobs in many cities have made home ownership less accessible to younger people (Martin et al. 2018). This trend has been worsened by the spread of austerity measures and a long-standing lack of investment in new social housing (Hess et al. 2018; Scanlon et al. 2014). Furthermore, although socio-spatial differentiation is also dependent on urban policy and planning (Marcińczak et al. 2016), and in some cases governments have successfully combated socio-economic segregation by way of, for example, social housing requirements in new developments (Andersson et al. 2010), local planning and land use policies frequently encourage construction of single-family homes (and entire neighbourhoods) for middle class households over affordable housing (Kovács 2020). The curtailment of socially-mixed urban housing options and pricing out of younger, lower-income population groups, especially from the most desirable inner-city areas, has resulted in the decentralisation of poverty, whereby low-income households, whether existing residents or newcomers, are increasingly funnelled into relatively isolated pockets of affordable housing and concentrated in the least desirable neighbourhoods (Hochstenbach, Musterd 2018; Kneebone, Nadeau 2015).

Of course, socio-economic segregation is not synonymous with social inequality and the degree to which segregation affects quality of life depends on historical, institutional and social contexts. Indeed, for urban areas characterised by relatively little income and wealth inequality, the consequences of segregation may be less problematic, but never without meaning (Maloutas, Fujita 2012). Bourdieu (2018) explains segregation as the manifestation of social hierarchies in space, driven by social struggles and mediated by the state. The relationship between social inequalities and segregation is furthermore highly contingent on the tendency of capitalist housing markets to concentrate social echelons in especially attractive urban areas with superior access to education, employment, and amenities as well as low levels of crime and pollution (Depro et al. 2015; Kuminoff et al. 2013). Hence, the capacity of segregation to aggravate social inequalities tends to be weakest in countries characterised by a strong redistributive welfare state and strongest in more liberal contexts (Maloutas, Fujita 2012).

While a complete overview of consequences linked to status-based segregation in general, and concentrations of poverty in particular, is outside the scope of this article, it is worth noting that social isolation and exclusion, poor access to education and employment opportunities, and neighbourhood stigma are counterproductive if not detrimental to the life quality and opportunities for people of all age groups (Galster, Sharkey 2017). Segregation may also have political repercussions; in Europe, several waves of migration to various regions have been met with a revival of right-wing populism and the normalisation of nationalist and even xenophobic discourse in everyday politics. This intolerance has been attributed in part to the catalysing effect of concentrations of racial or religious minorities on misunderstandings between communities and political alienation (van Leeuwen, Vega 2021). Contrariwise, high levels of social contact between groups can facilitate tolerance and understanding (Piekut, Valentine 2017). In sum, given socio-economic segregation may act as a catalyst of social inequalities and a threat to pluralist democracies, it is imperative to understand its causes and conditions across various contexts.

\section{Urban shrinkage and socio-spatial change in (post-)socialist Europe}

After the Second World War, countries of CEE either became Soviet republics or satellites 
subjected to a socialist political and socio-economic development agenda under the Soviet sphere of influence. For nearly half a century, they constituted a distinct geopolitical region between Western Europe and the Soviet Union, where the role of the market was drastically limited, collective ownership of land and infrastructure was prioritised, homogenisation and egalitarianism were the main societal directives, and resources were allocated according to the centralised planning system (Kovács 2020). Compared to capitalist cities, French and Hamilton (1979) found socialist cities of CEE generally featured a more diverse spatial mix of social groups, or, in other words, lower levels of socio-economic segregation. This was made possible by the high level of control governments held over local processes of spatial planning and management. Essentially, the state became the dominant actor in urban housing, which was proclaimed to be a universal right. As capitalist modes of housing were effectively abolished, most properties of the former bourgeoisie were confiscated and transferred to public ownership; however, certain inequalities persisted and new forms of segregation emerged. In the GDR, while income-based segregation was largely absent from cities, discrimination in the form of politically distributed privileges was common (Häussermann 1996). Elsewhere, such as in Poland, Hungary, and the Balkans, socio-economic inequalities were made possible by the existence of a secondary economy, which gradually evolved alongside the centrally planned economy and provided additional income for some households (Kovács 2020).

In the thirty years since the collapse of state socialism sparked far-reaching social and economic reforms, cities across CEE have followed distinctive paths of urban development and socio-spatial restructuring. On the one hand, the transition to a capitalist market economy and accession to the European Union presented numerous structural changes including deindustrialisation, globalisation, suburbanisation, sprawl, outmigration, and decreasing fertility rates. In many cases, one of the cumulative effects of these forces has been short- to long-term periods of urban shrinkage (Berentsen 1996; Steinführer, Haase 2007; Stryjakiewicz, Jaroszewska 2016). Within CEE, the region of eastern Germany, or the former GDR, serves as an interesting case since, due to the unique conditions surrounding German reunification, it is the only instance of a former centrally planned economy integrating into an existing market economy. Virtually overnight, eastern German cities were faced with various structural changes affecting their development. Subsequently, many medium-sized cities that were prioritised as centres of growth under state socialism, including once booming industrial hubs (e.g. Hoyerswerda, Schwedt, Weißwasser) and former district capitals (e.g. Gera, Suhl), endured drastic rates of depopulation and job losses (Heider 2019). Looking ahead, despite a handful of cities which have managed to buck negative population growth, thanks largely to an influx of youth and migrants, there is currently no strong indication of a reversal of the general trend of urban shrinkage in eastern Germany. Indeed, while well-connected, large cities like Berlin and Leipzig, and distinguished capitals or university cities like Dresden, Jena, and Potsdam are expected to continue growing after stints of depopulation, such cities are exceptions to the rule (Vogel 2020). Several authors maintain that eastern Germany's post-socialist transition represents a rare natural laboratory for studying how drastic institutional and economic changes affect urban systems, and thereby can serve as a frame of reference for future developments in other countries (Berentsen 1996; Heider 2019; Steinführer, Haase 2007). On the other hand, the impacts of the post-socialist transition on socio-spatial change and differentiation have also been curbed by legacies of state socialist policy and planning. In some cities, the transition led to an influx of younger and highly educated households to inner-city areas which were overrepresented by the elderly or vulnerable social groups - an aftereffect of the typically poor condition of pre-war buildings in many CEE cities following years of deliberate underinvestment and neglect - and thereby resulted in increased social mixing, at least in the short term (Kovács 2020; Sýkora 2009). Marcińczak et al. (2015) examined levels and patterns of socio-economic segregation in the capitals of so-called 'fast-track reforming' post-socialist countries (Czechia, Estonia, Hungary, Lithuania, and Poland) by referring to occupational structure of the economically active population and found certain legacy effects of state socialist policies, such as inherited urban 
forms or regulated rents in the case of Prague, offset the catalysing effect of economic liberalisation, globalisation, and growing income inequality on patterns of socio-economic segregation during the 1990s. Across all cases, irrespective of the extent of socialist-era development, the most and least coveted neighbourhoods of the city under and prior to state socialism had largely retained their desirability or lack thereof by the turn of the millennium. Interestingly, although city-wide levels of segregation and the share of middle social groups were similar across all cases, intra-urban concentrations of both lower and higher groups were far more pronounced in Tallinn and Vilnius than in the larger post-socialist capitals under consideration, namely Budapest, Prague, and Warsaw. These differences may be partly explained by the divergent nature and pace of post-socialist institutional changes across countries; in the Baltics, economic liberalisation and the retrenchment of the welfare state was more extensive than in Czechia, Hungary, and Poland. This led to more rapid growth of income and wealth inequality and, in turn, more pronounced spatial polarisation of differing social groups in the Baltic capitals (Marcińczak et al. 2015).

While most existing empirical studies of socio-spatial change and socio-economic segregation dynamics set in European cities weigh the influence of macro-processes such as deindustrialisation, globalisation, or economic inequality on city-wide levels or intra-urban patterns of socio-economic segregation (Marcińczak et al. 2016), a small but growing body of research considers how local processes of urban shrinkage shape socio-spatial disparities. Fol (2012) described how declining investment in French shrinking cities tended to fuel further job losses and selective outmigration of the youngest and most qualified residents, and thereby higher concentrations of unemployment and poverty. Under these conditions, many less affluent households, which suffer most from the social consequences of unemployment and urban decline, became trapped in marginalised neighbourhoods, while more affluent households frequently relocated to coveted areas. Comparing the experiences of three large post-socialist shrinking cities, Großmann et al. (2013) concluded shrinkage may act as a catalyst for social segregation, leading to pockets of rapid change and decline. In the case of Genoa, shrinkage triggered increasing concentrations of migrants in the historic city centre; in Leipzig, concentrations of unemployed residents and ethnic minorities in older working-class neighbourhoods characterised by high vacancy rates; and in Ostrava, increasing exclusion of the Roma minority population. Regarding Leipzig, Großmann et al. (2015) found that as the city declined in population during the 1990s, levels of residential mobility peaked and certain districts experienced a nearly complete reshuffling of residents. Here, city-wide housing oversupply and falling property values opened up niches for vulnerable population groups and minorities, above all in substandard housing in the least desirable neighbourhoods. Namely, the unemployed population became increasingly concentrated in unmodernised large socialist-era housing estates on the city's periphery, and non-native residents in select inner-city pockets characterised by decay. In terms of residents' average age, inner-city districts experienced an influx of youth whereas outer core and suburban areas grew older. Given that depopulation and vacancies strongly correlated with concentrations of vulnerable groups, the authors conclude urban shrinkage contributed to the city's socio-spatial restructuring and a partial reinstatement of pre-war patterns of socio-spatial differentiation. More recently, Haase et al. (2016b) reviewed the effects of urban shrinkage in several post-socialist cities (Halle, Leipzig, Ostrava, Bytom, Sosnowiec, Timişoara, Donetsk, and Makiivka) and found the post-socialist transition led to reshuffling of socio-spatial patterns in the first place, but also that local conditions of urban shrinkage and neoliberal policy responses to shrinkage-related challenges, such as labour market mismatches and housing oversupply, further aggravated socio-spatial segregation and intra-urban inequalities. Paradoxically, however, while increasing levels of socio-economic segregation and corresponding social problems have been observed under conditions of urban shrinkage in several post-socialist cities (Cortese et al. 2014; Maes et al. 2012), others-including Łódź and Vilnius - suggest this outcome is not necessarily inevitable. In such cases, certain legacy effects of state-socialist planning and policy have apparently offset the possible catalysing effect of shrinkage on socio-economic segregation (Marcińczak et al. 2012; Valatka et al. 2016). 
Although post-socialist cities have caught up with western cities in terms of empirical studies on shrinkage and socio-spatial change, the literature still lacks research on post-socialist cities at lower-tiers of the urban hierarchy (Brade et al. 2009; Steinführer 2006; Sýkora 2009). This is a notable gap, since lower-tier cities may be especially predisposed and susceptible to the myriad of challenges presented by shrinkage (Gentile 2003; Maes et al. 2012; Steinführer, Haase 2007). Kovács (2020) suggests this is partly because under the unstable societal conditions of the post-socialist transition, it has been difficult to make decisive judgements about long-term segregation processes. The scarcity of reliable data has also impeded empirical interest in the socio-spatial restructuring of post-socialist cities. Regarding eastern German cities, the omission of lower-tier cities in the existing literature on socio-spatial change may be explained by the absence of small-scale data on individual or household incomes, the postponement of the census after German reunification until 2011, and the relatively strict regulations on census data, including the inability to obtain intra-urban level data on education or occupation. Fortunately, data on income, education, or occupation are just a few possible indicators of socio-economic status. For example, Friedrichs and Triemer (2009), Helbig and Jähnen (2018), and Blokland and Vief (2021) examined levels and patterns of socio-economic segregation in various German cities by referring to data on unemployment, social assistance, or child poverty.

\section{Methodology}

The focus of this study lies on residential segregation of differing socio-economic population groups under conditions of urban shrinkage. In light of its recent experiences with shrinkage, the medium-sized city of Schwerin was selected as a case. ${ }^{1}$ Although Schwerin's population has stabilised since 2017, it still exhibits symptoms of shrinkage-including negative natural population growth, an unbalanced labour market and

In Germany, the lower and upper bounds for cities to be categorised as medium-sized are 20,000 and 99,999 residents, respectively. a persistent oversupply of housing - that affect processes of socio-spatial change and patterns of socio-economic segregation. Schwerin also proved suitable as the necessary intra-urban data were available. In line with previous empirical research of this nature, socio-economic groups are operationalised by referring to social security and labour market data. Namely, this study examines levels and patterns of segregation of (1) recipients of social assistance benefits under the age of 65 according to Book 2 of the German Social Code (SGB II); (2) working-age recipients of unemployment insurance according to SGB II; and (3) employed persons subject to social security contributions. Although the available data do not account for all social groups or allow for analyses of the highest social strata, they represent the best available spatial measure of socio-economic status for the case in question. The primary spatial unit is the city district and the temporal frame of analysis spans from 2000 until 2017, since neither the number of districts nor their boundaries changed during this period. ${ }^{2}$

Following an overview of the case and its historical context, the empirical analysis proceeds in three stages. First, Schwerin's districts are categorised into differing types of social areas, including inner-city quarters, socialist-era housing estates, and suburban zones at the periphery. Second, levels and patterns of socio-economic segregation are examined. To evaluate the spatial evenness of the aforementioned population groups, the indices of segregation (SI) and dissimilarity (DI) are employed. ${ }^{3}$ While such indices admitted-

2 While labour market figures are comparable for the years 2000 to 2017, due to reforms to Germany's social assistance system, data on social assistance recipients are only comparable from 2005 to 2017.

3 The SI indicates the share of a given group that would have to move in order to be evenly distributed across a city, and thereby offers a general assessment of the level of segregation. The SI is calculated as: $\mathrm{SI}=0.5 \times \sum\left[\left|x_{i} / X-y_{i} / Y\right|\right]$ where: $x_{i}$ is the population of group $X$ in spatial unit $i$; $X$ is the total population of group $X$ in a city; $y_{i}$ is the remainder of the population in spatial unit $i$; and $Y$ is the remainder of the population in a city. The DI is a variant of the SI that explicitly compares the distribution of two different groups within a larger population. The only difference to the formula is that $y_{i}$ refers to the population of group $Y$ in spatial unit $i$ and $Y$ to the total population of group $Y$ in a city. Values for both SI and DI, which may be interpreted as percentages for the sake of simplicity, 
ly only serve as a rough measure of segregation, they are well suited to capture broad changes in the distribution of multiple population groups across an urban area over time. In order to add some geography to the analysis, location quotients (LQ) are then used to map and compare concentrations of vulnerable population groups at select intervals. ${ }^{4}$ The years 2000/2005, 2010, and 2017 were chosen because they mark key developments in Schwerin's population change and housing market, as described below. Lastly, correlation analyses are conducted to examine the spatial interrelation between urban shrinkage, operationalised as housing oversupply, and intra-urban concentrations of vulnerable social groups over time. To conclude, the observed levels and patterns of segregation in Schwerin are summarised and discussed in relation to the existing literature.

\section{Setting the scene of the medium-sized post-socialist city: Schwerin, Germany}

Founded in 1160 by Henry the Lion, Schwerin $\left(53^{\circ} 38^{\prime} \mathrm{N}, 11^{\circ} 25^{\prime} \mathrm{E}\right)$ was integral to the duke's aim of eastward expansion, but its relative remoteness and distance from maritime trading routes hindered its economic prospects compared to similar-sized cities along the Baltic Sea. Consequently, Schwerin's early development was essentially shaped by its function as a bishop's seat and royal residence; a role which was further solidified in the sixteenth century with the construction of Schwerin Castle and its baroque gardens. The nineteenth century marked another formative phase in Schwerin's development; its

range from 0.0 (no segregation) to 1.0 (complete segregation). Values $<0.3$ are considered low whereas values $>0.6$ are interpreted as high (Massey, Denton 1988).

4 The LQ indicates patterns of spatial concentration of a given group across a city. The LQ is calculated as: $\mathrm{LQ}=\left(x_{i} / t_{i}\right) /(X / T)$ where $x_{i}$ and $t_{i}$ are the group $X$ population and the total population in spatial unit $i$; $X$ is the total $X$ population; and $T$ is the total population of a city. A value of 1.0 indicates that the share of group $X$ in unit $i$ perfectly resembles the distribution of group $X$ across the city. Values $>1.0$ indicate an overrepresentation of group $X$ relative to the citywide distribution, while values $<1.0$ indicate an underrepresentation (Brown, Chung 2006). connection to Berlin and Hamburg by rail, the construction of its still-standing Gründerzeitstyle central station, and the arrival of electric streetcars made the city not only more accessible, but also a more desirable place to live. After watching its population increase from just a few thousand to greater than 45,000 in less than a century, Schwerin's development was halted by the First World War; however, it resumed growing - and expanding spatially - during the interwar period following the incorporation of several surrounding villages. The city also managed to successfully renew its role as an important cultural centre, a desirable event venue, and popular tourist destination, which led to investments in hotels, restaurants, trades, and transport (Bock 2002; Krieck 1990). Possibly owing to its lack of war-related industries, Schwerin's cityscape escaped the Second World War largely unscathed and very few of its residential buildings were destroyed. Notwithstanding, Schwerin struggled with a housing shortage as waves of migrants and refugees sent its population soaring from about 65,000 in 1939 to an estimated 107,000 in 1945. After the War, Schwerin was placed under the administration of the Soviet Union and its population plummeted as more than 10,000 fled to West Germany leading up to the establishment of the GDR (Ohle, Ende 1994).

Schwerin subsequently experienced considerable growth due to its administrative functions as a district capital of the GDR as well as its prioritisation as a rail and commercial hub for the dairy and agricultural industries. However, the construction of new housing for Schwerin's rapidly growing population did not commence in earnest until 1955, at which point development began on the district of Weststadt in an area well-suited for industrial housing construction at the edge of the city. While, until 1962, all new residential buildings were built in the style of traditional low-rise apartment blocks, the following years were characterised by the near-exclusive construction of larger prefabricated towers-including more than 10,000 apartments in the districts of Weststadt and Lankow - in order to densify the housing stock and save on costs (Ohle, Ende 1994). In 1972, Schwerin's population exceeded 100,000 and ground broke on the construction of its largest industrial zone, propelling further growth of the city's mechanical 
engineering, cables, metals, plastics, textile, brewing, and publishing industries. Overwhelming housing demand meanwhile led to the construction of Schwerin's largest ensemble of medium- to high-rise prefabricated apartment blocks in the adjacent districts of Dreesch I, Dreesch II, and Dreesch III (today Großer Dreesch, Neu Zippendorf, and Mueßer Holz). Underscoring the one-sided orientation of urban development, upwards of 30,000 such apartments for approximately 60,000 residents were erected in these outer-city districts during the 1970s and 1980s. Schwerin's historic inner-city, which meanwhile had been largely neglected by centralised planning priorities, became a target of redevelopment in the mid-1970s, relatively late compared to other district capitals. Although plans to transform the inner-city into a modern metropolis were never realised, the apparent indifference among locals to the proposed redevelopments may be explained by the then overly dilapidated state of most pre-war buildings, which had caused many inner-city residents to relocate to newly-built prefabricated apartments on the city's outskirts by the 1970s (Bock 2002). In sum, Schwerin's spatial structure was transformed from monocentric to polycentric during the era of state socialism. Peripherally-located areas of new prefabricated housing experienced a population boom, while historic inner-city areas fell into a state of physical and social deterioration. While some medium and higher strata households remained in the inner-city, occupying the few remaining good-quality tenements, the social status of residents generally increased with increasing distance from the city centre.

In 1988, Schwerin recorded its peak population of 130,685; however, the fall of the Berlin Wall in 1989 and the city's subsequent integration into the system of market-based capitalism and exposure to globalisation triggered profound social and economic change. Although Schwerin retained its role as state capital, the industries that sustained its growth under state socialism faced a substantial breakdown. Consequently, rising unemployment, a labour market mismatch, and economically-driven outmigration became a few of the most salient outcomes of the post-socialist transition. As illustrated in Figure 1, in the first decade of its transition alone, due to persistent migration losses and below replacement-level fertility rates, Schwerin lost more than 30,000 residents - nearly a quarter of its population (Stadt Schwerin, 2015).

Schwerin's declining demographic and economic conditions also affected its housing market; after 1990, as the government stepped aside, new developments became increasingly initiated by the private sector or individual households. Owing to the sudden demand for single-family homes and suburban lifestyles, several large residential areas were developed along Schwerin's

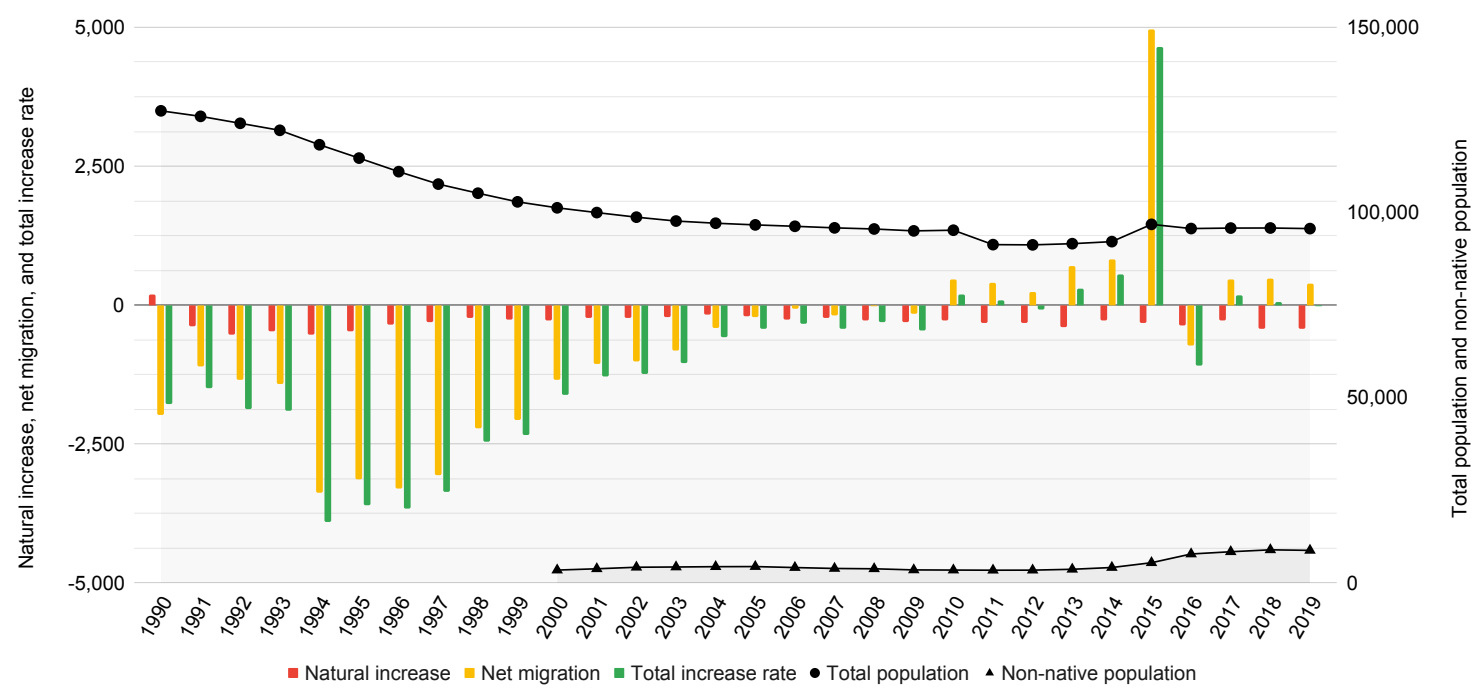

Fig. 1. Population dynamics and growth in Schwerin, 1990-2019. Source: author's elaboration based on Stadtverwaltung Schwerin (2021). 
western periphery. Meanwhile, as in numerous other eastern German cities, housing vacancies skyrocketed in Schwerin during the 1990s. Besides outmigration and declining birth rates, this oversupply was initially facilitated by the widespread privatisation of municipal housing stocks in eastern Germany during the initial years of transition. During the mid to late 1990s, waves of generous state subsidies and tax incentives aiming to encourage urban development and renewal, above all in historic inner-city districts, resulted in additional surpluses as hundreds of newly built and refurbished dwellings were added to the market (Großmann et al. 2015; Stadt Schwerin, 2015). This glut of market-active vacancies led to falling rental fees in Schwerin. In 2003, the average rent for a newly built apartment was $24 \%$ lower than in 1997, while for flats in renovated pre-1956 buildings and housing estates built between 1956 and 1990, average rents decreased by 11 and 14\%, respectively. However, given fixed costs and maintenance expenses incurred by property owners remained stable or, even more likely, increased despite Schwerin's ongoing depopulation and oversupply, average rents remained fairly static throughout the 2000s, even for unrenovated flats, before returning to 1997 levels in the mid-2010s (Fig. 2).

In this regard, it should be noted that owing to legacies of socialist policy as well as Germany's contemporary housing market model, rental housing comprises the predominant tenure form in Schwerin. Indeed, although extensive construction of owner-occupied single-family housing after 1990 caused the share of households renting to decrease from approximately 93 to $75 \%$ between 1995 and 2011, renting remains first and foremost an option for a significant proportion of residents representing a wide range of socio-economic groups. Especially from the mid-1990s to mid-2000s, the combined effect of Schwerin's rental dominated market, housing oversupply, and low rental fees was a noticeable increase in residential mobility (Gerdes et al. 2003; Stadt Schwerin, 2015).

Socialist-era housing estates located outside Schwerin's historic city centre also received upgrades leading up to and after 2000, albeit to a lesser degree. High vacancy rates among housing estates, however, became the focus of state-subsidised rightsizing efforts following the introduction of Stadtumbau Ost in 2001, a federal programme designed to stabilise eastern German housing markets using targeted demolition and urban renewal measures. In the first decade of the programme, Schwerin dismantled roughly 4,800 apartments - above all in Großer Dreesch and Mueßer Holz-and in so doing managed to reduce its vacancy rate from approximately 13 to $9 \%$ between 2004 and 2013 despite

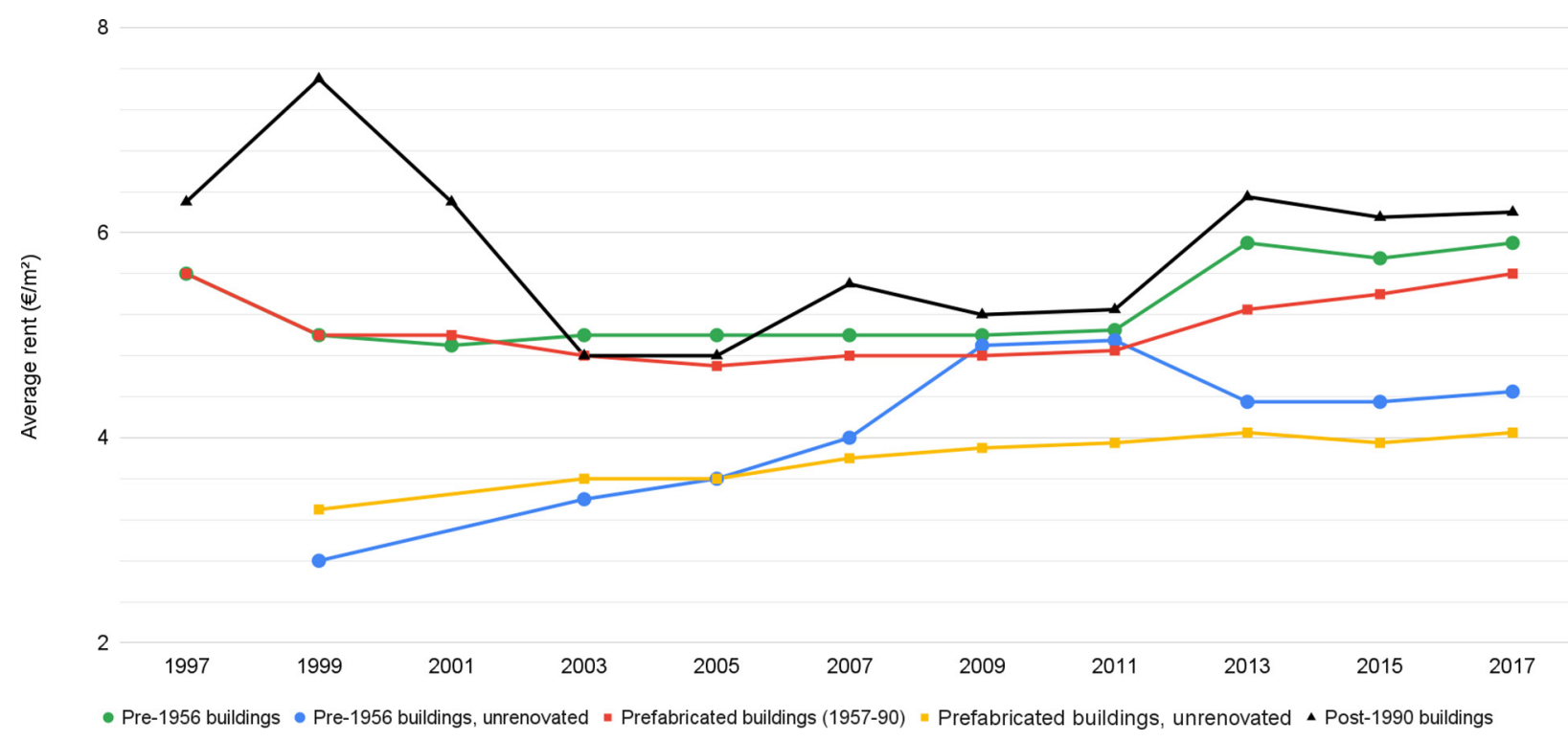

Fig. 2. Average monthly rents per $\mathrm{m}^{2}$ for different housing types in Schwerin, 1997-2017. Source: author's elaboration based on Stadtverwaltung Schwerin (2021). Note: Rents refer to a good quality apartment of approximately $60 \mathrm{~m}^{2}$ and exclude utility costs. As of 2011, nearly every third building was built before 1956, roughly half were completed between 1957 and 1990, and the remaining were erected after 1990 (Stadt Schwerin, 2015). 
continuing population decline (Stadt Schwerin, 2015). Notwithstanding city-wide revitalisation efforts, in 2012, Schwerin's population reached its lowest level since the Second World War, with 91,264 residents. On the other hand, after nearly two decades of negative net migration, Schwerin recorded positive migration inflows during most of the 2010s. Particularly striking is the sharp increase of newcomers in 2015 and 2016, predominantly young persons and families seeking asylum. Today, Schwerin's economy is dominated by the service sector, small businesses, as well as larger companies in the food industry, cable and aerospace manufacturing, environmental engineering, and plastics processing. Schwerin is also the site of several governmental authorities, a tertiary care institution and teaching hospital, and two applied universities. Hence, just as in larger eastern German cities, the overriding influence of the liberalisation of cross-border trade and spread of neoliberal economic policy has been a reorganisation of Schwerin's socio-economic foundations towards post-Fordism. However, whereas in prosperous cities the local economy tends to shape paths of spatial development, economic growth has had limited relevance for Schwerin's post-socialist spatial restructuring under the conditions of urban shrinkage. While Schwerin's population has stabilised somewhat since 2017, the city is still facing the impacts of urban shrinkage today. The consequences include above all residential and commercial vacancies, brownfields and perforations, and underused infrastructure. However, not all areas are equally affected; while inner-city and suburban areas are characterised by stable or growing populations and low vacancy rates, the districts found in-between continue to face processes of shrinkage including selective outmigration, housing oversupply, and abandoned space. Accordingly, urban shrinkage remains an important matter for local decision-makers (Stadt Schwerin, 2015).

\section{Results: Schwerin's socio-spatial restructuring}

Besides a range of urban forms and architectural styles, each of Schwerin's 24 inhabited districts are characterised by differing levels of modernisation and access to amenities and infrastructure, such as green spaces and public transport. Notwithstanding, Schwerin can be broadly divided into the following types of three areas: (1) dense, inner-city districts with a mixed socio-economic function and high proportion of pre-war buildings; (2) outer core districts with a predominantly residential function and high proportions of large prefabricated housing estates built in the 1960s to 1980s; and (3) suburban districts on the city's outskirts with a predominantly residential function and high proportion of owner-occupied single-family dwellings. Districts exhibit a wide range of population trajectories: between 1997the first year for which reliable intra-urban population data are available - and 2017-the most recent year for which comparable data are available and point at which Schwerin's population has stabilised, 14 of 24 districts increased in population while the remaining shrunk. Strong growth was recorded in suburban districts, where a boom of single-family housing construction occurred during the 1990s, but also in redeveloped inner-city quarters. Districts with large housing estates meanwhile are characterised by significant rates of population decline.

The highest levels of growth occurred in the suburban districts of Gartenstadt, Warnitz, and Neumühle, all three of which roughly doubled in population between 1997 and 2017, from 1,137 to $2,452(+116 \%)$, from 757 to 1,572 $(+108 \%)$, and from 1,558 to $3,006(+93 \%)$, respectively. Noticeable growth was also recorded in the inner-city districts of Altstadt, Feldstadt, Paulsstadt, Schelfstadt, and Werdervorstadt, which altogether increased from 19,698 to 26,451 residents between 1997 and 2017, but also in the smaller suburban districts of Wickendorf and Zippendorf. The shrinking districts, which include all five large housing estates plus five suburban districts, also exhibit varying degrees of depopulation between 1997 and 2017, with the largest losses in the housing estates of Neu Zippendorf and Mueßer Holz, which decreased from 10,426 to $5,195(-50 \%)$ and from 21,029 to $10,976(-48 \%)$, respectively. The next largest losses occurred in two of the remaining three housing estates, namely Großer Dreesch $(-24 \%)$ and Lankow $(-21 \%)$, followed by the suburban district of Görries (-21\%). Notably, the only housing estate which didn't experience significant depopulation during the period in question, 
Weststadt, which decreased in population from 12,765 to 11,378 between 1997 and 2017, is the only estate that predominantly includes lowrise prefabricated buildings, while the other four have greater shares of mid- to high-rise prefabricated blocks. Weststadt is also noticeably closer to the city centre and central railway station. Rates of depopulation have varied over the years; among housing estates, relatively continuous depopulation was observed in Lankow and Neu Zippendorf, whereas a wave of migration in 2015 caused population increases in Großer Dreesch and Mueßer Holz following two decades of decline. Some inner-city districts, including Feldstadt, Schelfstadt, and Werdervorstadt, suffered consistent losses during the 1990s before entering a phase of reurbanisation in the 2000s following building upgrading efforts and infill development.

While some degree of socio-economic segregation is arguably unavoidable in cities like Schwerin, where each district's desirability is reflected in property values and rental prices, the development of SI values for select social groups in Schwerin as depicted in Figure 4 reveal not only the presence of socio-economic segregation, but also a clear trend: namely, both disadvantaged and better-off social groups became increasingly less evenly distributed across the city during the periods under investigation.

Segregation of social assistance recipients under the age of 65 increased by 15\% between 2005 and 2017. While the fact that, in 2005, roughly $30 \%$ of social assistance recipients would have had to relocate to a different district in order to

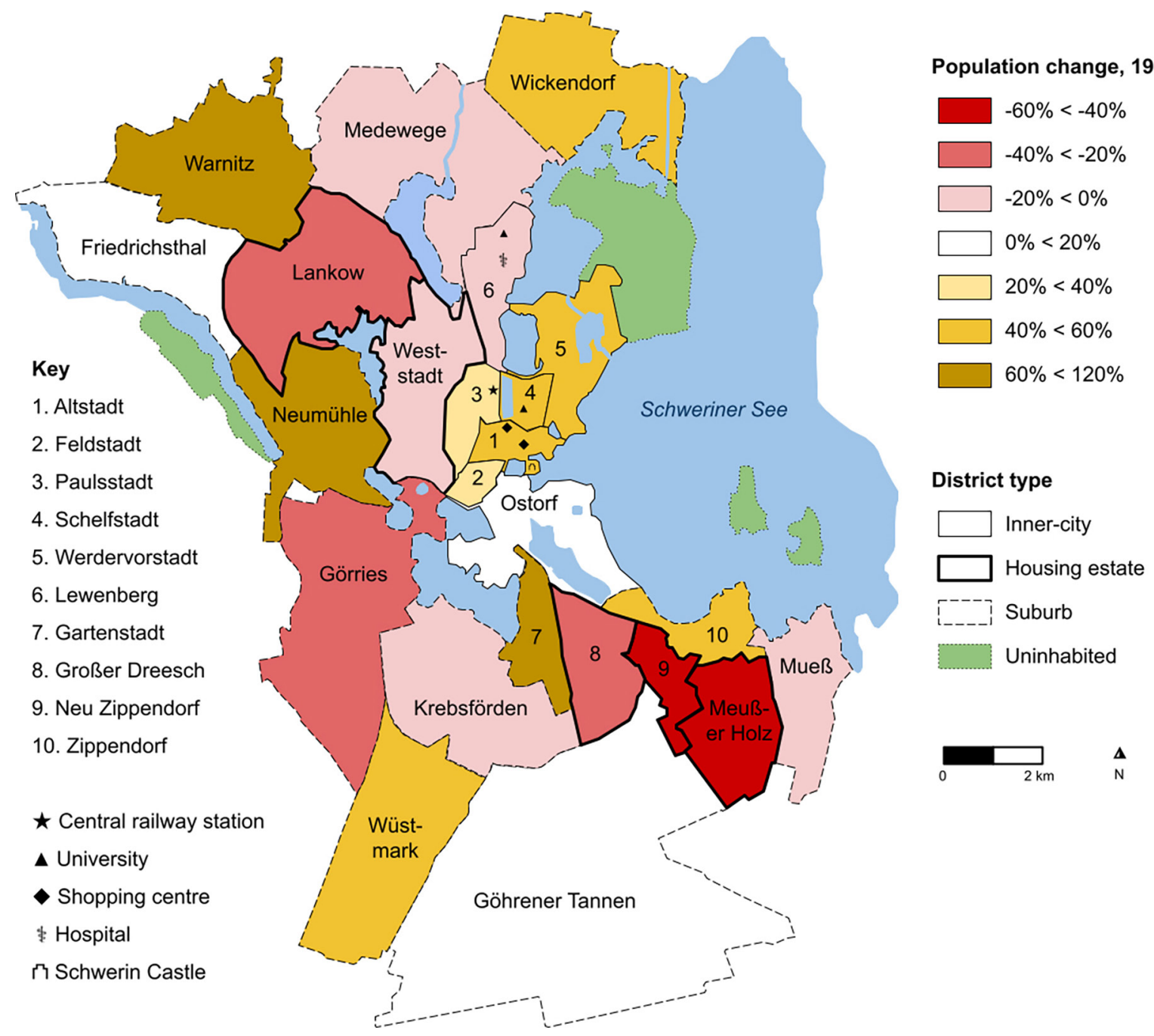

Fig. 3. Population change in Schwerin by district, 1997-2017. Source: author's elaboration based on Stadtverwaltung Schwerin (2021). 


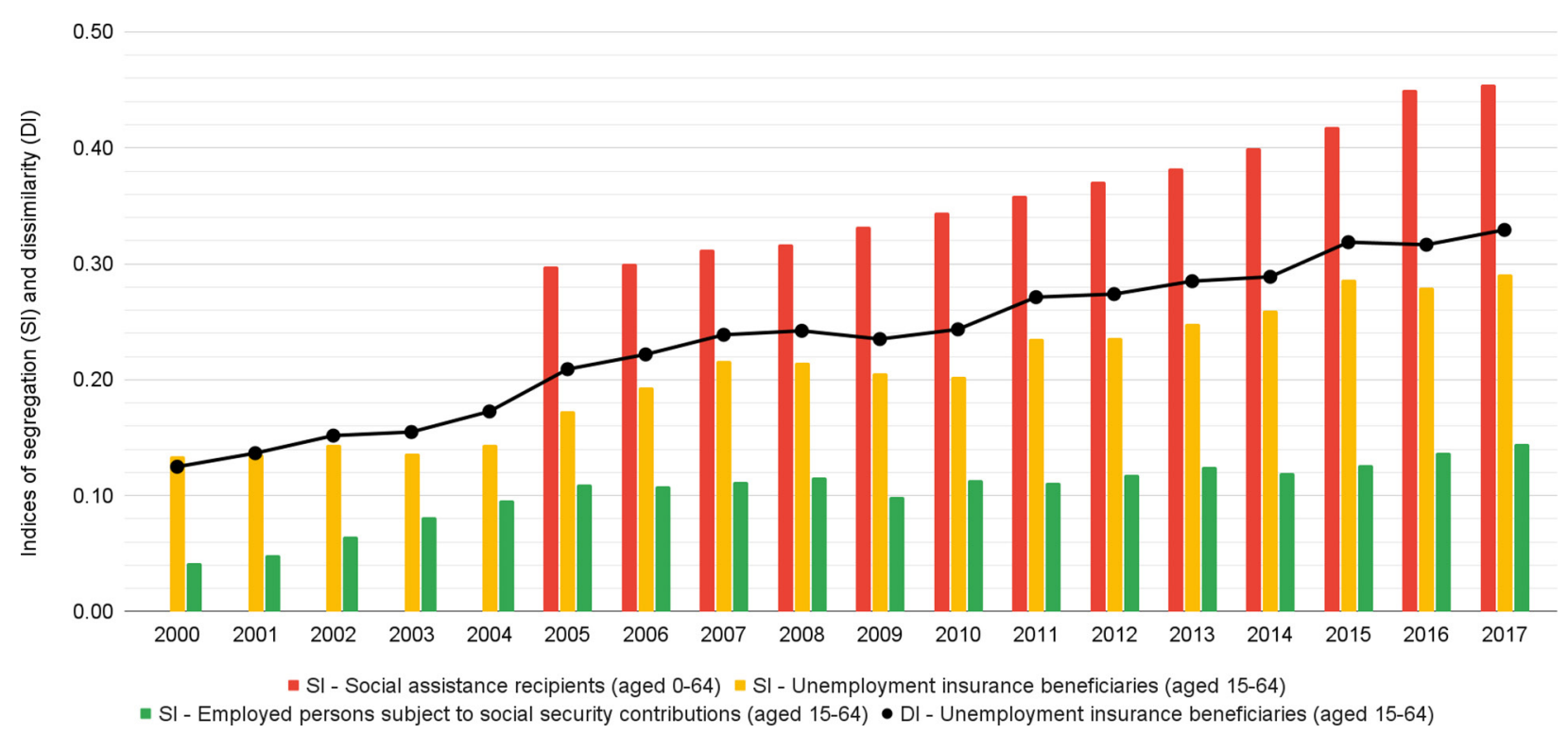

Fig. 4. Indices of segregation (SI) and dissimilarity (DI) for socio-economic population groups in Schwerin, 2000-2017.

Source: author's elaboration based on Stadtverwaltung Schwerin (2021).

achieve an equal distribution across the city does not necessarily establish continuous growth of segregation between 1990 and 2005, lower levels of segregation can be assumed, at least during the early 1990s, given that, firstly, relatively low levels of socio-economic segregation were typical of socialist cities and, secondly, Schwerin recorded a three-fold increase in social assistance recipients-from about 2,700 to 8,032 personsbetween 1994 and 2003 (Gerdes et al. 2003). However, that this value reached $45 \%$ in 2017 signals relatively high levels of segregation among Schwerin's most vulnerable social groups in addition to growing spatial polarisation between poverty and affluence.

Regarding SI values for unemployment insurance beneficiaries and employed persons subject to social security contributions, overall increases of $16 \%$ and $10 \%$ were observed between 2000 and 2017, respectively. The development of DI values additionally shows that residents receiving unemployment benefits became roughly $21 \%$ more segregated from the actively working population over the same period. While these findings confirm the unemployed and employed are increasingly living in different areas, the latest values of SI and DI, which range between 14 and 33\%, do not signal polarisation but rather medium levels of segregation (Marcińczak et al. 2016).

Figures 5 and 6 illustrate the developing intra-urban patterns of socio-economic segregation in Schwerin's districts between 2000 and 2017. LQ values reveal that districts with the most marked overrepresentations of disadvantaged groups increasingly overlap with shrinking districts, especially those with a predominance of prefabricated high-rise housing estates. Furthermore, growing concentrations of upper social groups can be observed among inner-city and suburban areas, the latter of which included barely any disadvantaged households in 2017. These trends, as in numerous other cities, are partly explained by urban revitalisation and suburbanisation. However, it seems that Schwerin's inherited macro spatial configuration has also had lasting consequences for its socio-spatial restructuring.

For one, inner-city districts as well as select housing estates still retained a relatively mixed social fabric in 2000. Evidently, continuous depopulation, suburbanisation, and selective building upgrading efforts during the 1990s had a negligible effect on socio-economic segregation in these areas. After 2000, however, many older apartment buildings in trendy inner-city districts which had yet to be the target of modernisation received their turn thanks to waves of public and private investment. Subsequently, inner-city areas flipped from negative to positive population growth and experienced a reshuffling of their social arrangements, especially growth of better-off households. While nearly all of Schwerin's housing estates were already 

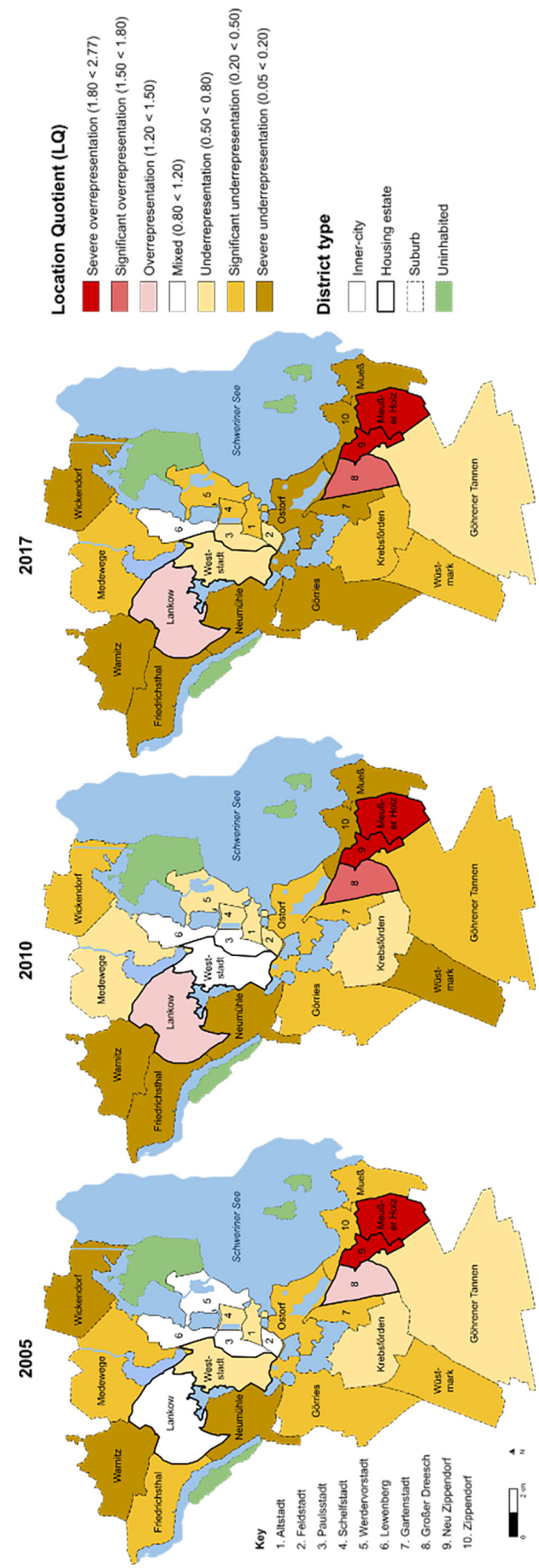
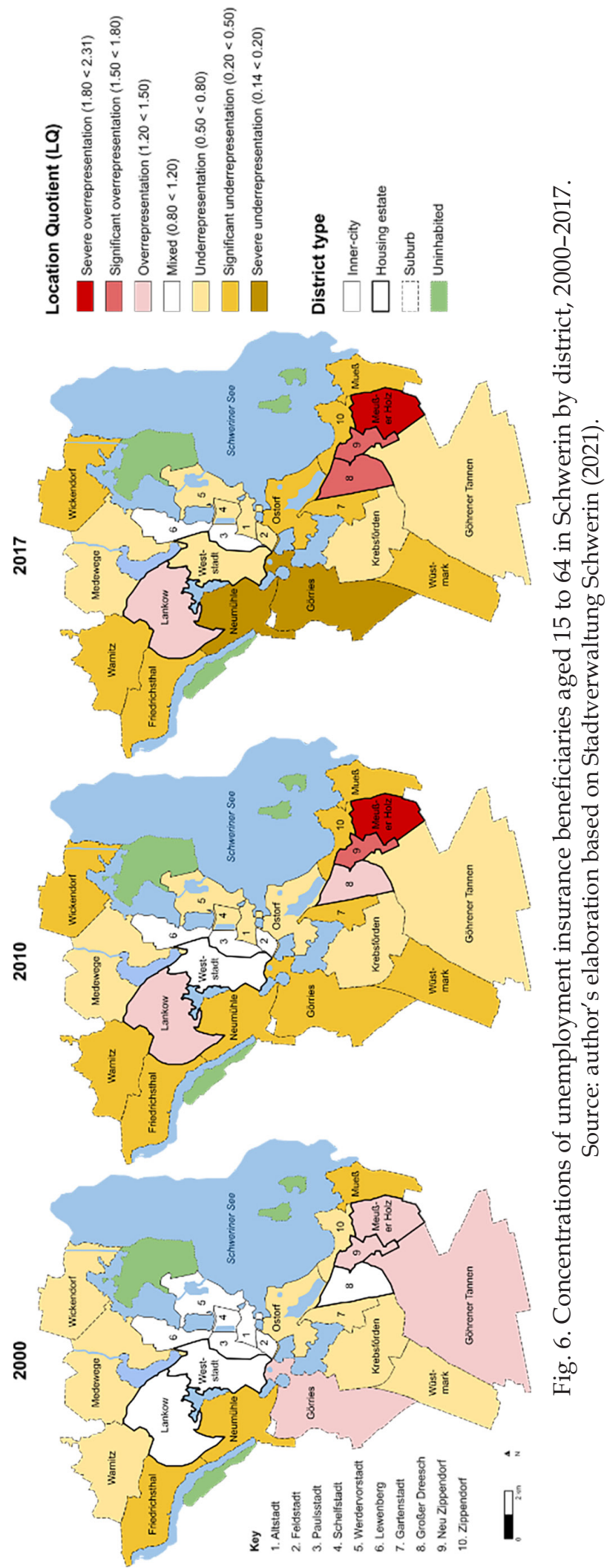
characterised by higher than average concentrations of vulnerable social groups in 2000/2005, these patterns have since intensified and become even more rigid. In addition, a general lack of social mixing was already apparent in suburban areas in 2000. Here, it seems a lack of restrictions on new suburban developments and the proliferation of single-family housing and condominiums during Schwerin's first year in transition contributed to higher concentrations of better-off groups.

Following the argument of Großmann et al. (2015) as well as Helbig and Jähnen (2018), Schwerin's persistent oversupply of housing has likely figured into emerging patterns of segregation since higher rates of vacancy and abandonment may inhibit rent increases in certain areas and thereby drive concentrations of socio-economically disadvantaged households. In order to gauge the significance of oversupply on patterns of socio-economic segregation in Schwerin, Table 1 examines the extent to which housing vacancy rates correlate with concentrations of vulnerable population groups at the district level.

The results indicate rather strong and increasing correlations between vacancy rates and concentrations of social assistance recipients as well as unemployment insurance beneficiaries. Evidently, higher than average vacancy rates led to below-average rents in less desirable districts and, consequently, growing shares of vulnerable socio-economic households. The interrelations were already present at the turn of the millennium but weakened somewhat during the 2000s as rightsizing efforts were undertaken to curb housing oversupply and strengthen the housing market. The strength and significance of these correlations increased after 2010, however, as state-subsidised demolition and upgrading efforts slowed, net migration balances flipped from negative to positive, and reurbanisation processes intensified in the city centre. Thus, district-level patterns of socio-economic segregation are indeed related to housing oversupply in Schwerin. Of course, as discussed above, Schwerin's rental dominated housing market structure plus its share of prefabricated housing estates facilitated the city's shrinkage and oversupply; ergo there is a contingent relationship between Schwerin's socialist-era institutional and morphological inheritances and its contemporary intra-urban patterns of socio-economic segregation.

\section{Discussion and summary}

The current debate on the socio-spatial effects of urban shrinkage falls short of a holistic understanding as we lack empirical studies set in the context of small and medium-sized cities, especially post-socialist cities of CEE, a recent hotspot of urban shrinkage. Consequently, existing theories about how processes of urban shrinkage affect socio-economic segregation have been predominantly developed on the basis of evidence from a limited context. Haase et al. (2016b) argue that post-socialist experiences with urban shrinkage may offer valuable insights for strengthening the discussion on urbanisation since new evidence concerning processes of shrinkage under conditions of institutional change may reveal blind spots in our understanding of the dynamics of urban change that are potentially generalisable to other contexts. Additionally, the experiences of post-socialist cities with institutional and structural change could offer lessons for resource-constrained (shrinking) cities around the world since these conditions may facilitate innovation in urban governance. An examination of the case of the medium-sized post-socialist city of Schwerin suggests processes of urban shrinkage

Table 1. Correlations of housing oversupply with concentrations of select vulnerable socio-economic groups in Schwerin, 2001-2017 (Pearson's $r$; ${ }^{*} p<0.05,{ }^{* *} p<0.01 ; n=24$ ).

\begin{tabular}{|l|c|c|c|c|c|c|c|c|c|c|}
\hline & \multicolumn{10}{|c|}{ Vacancy rates } \\
\cline { 2 - 10 } & 2001 & 2003 & 2005 & 2007 & 2009 & 2011 & 2013 & 2015 & 2017 \\
\hline $\begin{array}{l}\text { Location quotient of social assistance } \\
\text { recipients }\end{array}$ & $\mathrm{N} / \mathrm{A}$ & $\mathrm{N} / \mathrm{A}$ & $\begin{array}{c}0.489^{*} \\
(0.015)\end{array}$ & $\begin{array}{c}0.425^{*} \\
(0.039)\end{array}$ & $\begin{array}{c}0.529^{* *} \\
(0.008)\end{array}$ & $\begin{array}{c}0.383 \\
(0.064)\end{array}$ & $\begin{array}{c}0.760^{* *} \\
(0.000)\end{array}$ & $\begin{array}{c}0.670^{* *} \\
(0.000)\end{array}$ & $\begin{array}{c}0.530^{* *} \\
(0.008)\end{array}$ \\
\hline $\begin{array}{l}\text { Location quotient of unemployment } \\
\text { insurance beneficiaries }\end{array}$ & $\begin{array}{c}0.477^{*} \\
(0.018)\end{array}$ & $\begin{array}{c}0.738^{* *} \\
(0.000)\end{array}$ & $\begin{array}{c}0.469^{*} \\
(0.021)\end{array}$ & $\begin{array}{c}0.399 \\
(0.054)\end{array}$ & $\begin{array}{c}0.533^{* *} \\
(0.007)\end{array}$ & $\begin{array}{c}0.405^{*} \\
(0.049)\end{array}$ & $\begin{array}{c}0.777^{* *} \\
(0.000)\end{array}$ & $\begin{array}{c}0.727^{* *} \\
(0.000)\end{array}$ & $\begin{array}{c}0.542^{* *} \\
(0.006)\end{array}$ \\
\hline
\end{tabular}

Source: author's calculations based on Stadtverwaltung Schwerin (2021). 
may influence levels of socio-economic segregation and patterns of intra-urban inequality. In Schwerin, selective outmigration and housing vacancies fuelled increases in residential mobility; however, existing and new residents receiving unemployment insurance, and to an even greater degree recipients of basic social assistance, were mostly unable to take advantage of a rise in market-active housing options in coveted inner-city or suburban districts as rental prices remained beyond their reach. In other words, increased residential mobility was selective and largely restricted to the better-off whereas vulnerable socio-economic groups were funnelled into more affordable albeit less desirable areas, namely peripherally-located housing estates built under state socialism. Furthermore, high vacancy rates and underinvestment in rightsizing measures may have exacerbated socially selective outmigration from these areas, triggering a self-reinforcing cycle of shrinkage and segregation. This situation is worsened by a growing reliance on social assistance among Schwerin's population and high demand for low-cost rentals, which, meanwhile, have become increasingly scarce in inner-city districts. Thus, the case of Schwerin disproves the common assumption that cities characterised by persistent outmigration and correspondingly high vacancy rates contain an abundance of affordable housing options.

Although one should be cautious when comparing segregation levels between cities, especially internationally, Schwerin's path of increasing socio-spatial inequality under conditions of institutional and structural change appears to echo the experiences of larger eastern German cities, such as Leipzig, as well as post-socialist capitals with exceptionally high shares of housing estates, like Vilnius (Großmann et al. 2015; Valatka et al. 2016). Additionally, comparisons may be drawn with cases of urban shrinkage outside the context of post-socialist Europe and rental-dominated housing markets. Specifically, the case of Parkstad Limburg, a former ind ustrial region in the south of the Netherlands, demonstrates that high rates of vacancy among owner-occupied dwellings may, not unlike vacancies among Schwerin's housing estates, exacerbate levels of socio-economic segregation and intra-urban divisions of rich and poor under conditions of urban shrinkage, economic decline, and selective outmigration (Hoekstra et al. 2020). The experiences of American cities including Detroit with depopulation and severe inner-city vacancy rates in the wake of the Great Recession likewise suggest that socio-economically disadvantaged groups may become trapped in owner-occupied, single-family housing dominated markets despite overall increases in residential mobility. Here, however, developer-driven suburbanisation as well as private acts of housing discrimination appear to have played a greater role in growing socio-spatial disparities under conditions of structural shrinkage (Galster 2012; Kneebone, Nadeau 2015).

Yet, Schwerin's contemporary experiences with socio-economic segregation cannot be explained by processes of urban shrinkage alone. Just as in larger post-socialist cities, market forces, including the neoliberalisation of housing, are underpinning mechanisms of segregation (Kovács 2020). Increasing inner-city real estate prices since the mid-1990s have limited new or rebuilt housing mainly to upper echelons. Moreover, the combined encouragement and subsidisation of new single-family housing in eastern German cities after 1990 effectively opened a window of opportunity for the better-off to self-segregate, above all in suburban areas. Lastly, the role of Schwerin's prefabricated housing estates on levels and patterns of socio-economic segregation cannot be overstated. In particular, the largest ensembles of estates dating from the heydays of the socialist-era have since become hotspots of socio-economically disadvantaged groups - a challenge facing numerous European cities (Hess et al. 2018). Given it cannot be taken for granted that the dynamics of shrinkage and segregation observed in Schwerin apply to other medium-sized (post-socialist) cities, it would be interesting to compare the results of this study with further cases characterised by differing urban forms and institutional contexts, especially lower-tier cities facing a shortage of (rental) housing. Additional comparative research testing the causal links between shrinkage and socio-economic segregation in medium-sized cities which exhibit dissimilar manifestations of and responses to shrinkage is also welcome.

To wrap up, as is often assumed in the literature but seldomly demonstrated, this study confirms that medium-sized cities are not immune to 
the potentially catalysing effect of urban shrinkage on socio-economic segregation nor intra-urban concentrations of affluence and poverty. That said, Schwerin is an exemplary case characterised by the simultaneous occurrence of several multi-scalar institutional and structural transformations over a short period, including macro political and economic reforms alongside deindustrialisation and a demographic transition, in addition to major shifts in labour and housing markets and residential mobility at the local scale. All of these changes have shaped the behaviours of residents and other housing market actors. Despite the specifics of the case, Schwerin's experiences with shrinkage and socio-spatial change offer relevant lessons for other contexts. Even though the population of Schwerin's inner-city districts has rebounded in recent years, its large housing estates, especially those located furthest from the city centre, continue to face population losses and high vacancy rates. Looking ahead, Schwerin's adaptation to processes of urban shrinkage will continue to be of utmost importance for the development of its socio-spatial fabric. While it remains to be seen if the city can reverse its course of increasing socio-economic segregation, there appears to be growing awareness of these interrelated wicked problems and interest among policy-makers in formulating integrated strategies that view shrinkage as an opportunity for promoting social cohesion as well as improving existing residents' residential satisfaction and general quality of life (Cortese et al. 2014; Helbig, Salomo 2019; Stadt Schwerin, 2015).

\section{Acknowledgements}

This project has received funding from the European Union's Horizon 2020 research and innovation programme under the Marie Skłodowska-Curie grant agreement No 813803 . The author thanks the two anonymous reviewers for their helpful comments.

\section{References}

Andersson R., Bråmå Å., Holmqvist E., 2010. Counteracting segregation: Swedish policies and experiences. Housing Studies 25(2): 237-256. DOI 10.1080/02673030903561859.

Berentsen W.H., 1996. Regional population changes in eastern Germany after unification. Post-So- viet Geography and Economics 37(10): 615-632. DOI 10.1080/10889388.1996.10641033.

Bischoff K., Reardon S.F., 2014. Residential segregation by income, 1970-2009. In: Logan J., (ed.), Diversity and disparities. Russell Sage Foundation, New York: 208-233.

Blokland T., Vief R., 2021. Making sense of segregation in a well-connected city: The case of Berlin. In: van Ham M., Tammaru T., Ubarevičienė R., Janssen H. (eds), Urban socio-economic segregation and income inequality: A global perspective. Springer International Publishing, Cham: 249-270. DOI 10.1007/978-3-030-64569-4_13.

Bock S., 2002. Umgestaltungspläne für die Schweriner Innenstadt zwischen 1933 und 1980 (Redevelopment plans for Schwerin's city centre between 1933 and 1980). In: Lichtnau B. (ed.), Architektur und Städtebau im südlichen Ostseeraum zwischen 1936 und 1980 (Architecture and urban development in the southern Baltic Sea Region between 1936 and 1980). Lukas Verlag, Berlin: 214-235.

Bourdieu P., 2018. Social space and the genesis of appropriated physical space. International Journal of Urban and Regional Research 42(1): 106-114. DOI 10.1111/14682427.12534.

Brade I., Herfert G., West K., 2009. Recent trends and future prospects of socio-spatial differentiation in urban regions of Central and Eastern Europe: A lull before the storm? Cities 26(5): 233-244. DOI 10.1016/j.cities.2009.05.001.

Brown L.A., Chung S.Y., 2006. Spatial segregation, segregation indices and the geographical perspective. Population. Space and Place 12(2): 125-143. DOI 10.1002/psp.403.

Cortese C., Haase A., Großmann K., Ticha I., 2014. Governing social cohesion in shrinking cities: The cases of Ostrava, Genoa and Leipzig. European Planning Studies 22(10): 2050-2066. DOI 10.1080/09654313.2013.817540.

Desmond M., Wilmers N., 2019. Do the poor pay more for housing? Exploitation, profit, and risk in rental markets. American Journal of Sociology 124(4): 1090-1124. DOI 10.1086/701697.

Depro B., O'Neil M., Timmins C., 2015. White flight and coming to the nuisance: Can residential mobility explain environmental injustice? Journal of the Association of Environmental and Resource Economists 2(3): 439-468. DOI 10.1086/682716.

European Commission, 2011. Cities of tomorrow: Challenges, visions, ways forward. European Commission, Brussels. DOI 10.2776/41803.

Fol S., 2012. Urban shrinkage and socio-spatial disparities: Are the remedies worse than the disease? Built Environment 38(2): 259-275. DOI 10.2148/benv.38.2.259.

French R.A., Hamilton F.I. (eds), 1979. The socialist city: Spatial structure and urban policy. John Wiley \& Sons, Chichester.

Friedrichs J., Triemer S., 2009. Gespaltene Städte? Soziale und ethnische Segregation in deutschen Großstädten (Divided cities? Social and ethnic segregation in German cities). VS Verlag für Sozialwissenschaften, Wiesbaden. Springer-Verlag. DOI 10.1007/978-3-531-91675-0.

Galster G., 2012. Driving Detroit: The quest for respect in the Motor City. University of Pennsylvania Press, Philadelphia. DOI 10.9783/9780812206463.

Galster G., Sharkey P., 2017. Spatial foundations of inequality: A conceptual model and empirical overview. The Russell Sage Journal of the Social Sciences 3(2): 1-33. DOI 10.7758/rsf.2017.3.2.01.

Gentile M., 2003. Residential segregation in a medium-sized post-soviet city: Ust'-Kamenogorsk, Kazakhstan. Tijd- 
schrift Voor Economische en Sociale Geografie 94(5): 589-605. DOI 10.1046/j.1467-9663.2003.00285.x.

Gerdes J., Jackisch A., Schützler C., 2003. Lagebericht zur sozialen Situation in der Landeshauptstadt Schwerin (Status report on the social situation in the state capital Schwerin). Bundesministerium für Bildung und Forschung, Bonn.

Großmann K., Haase A., Arndt T., Cortese C., Rink D., Rumpel P., Slach O., Ticha I., Violante A., 2013. How urban shrinkage impacts on patterns of socio-spatial segregation: The cases of Leipzig, Ostrava and Genoa. In: Camp Yeakey C., Wells A., Sanders Thompson V. (eds), Urban ills: Twenty-first-century complexities of urban living in global contexts. Lexington Books, Lanham: 241-268.

Großmann K., Arndt T., Haase A., Rink D., Steinführer A., 2015. The influence of housing oversupply on residential segregation: Exploring the post-socialist city of Leipzig. Urban Geography 36(4): 550-577. DOI 10.1080/02723638.2015.1014672.

Haase A., Bernt M., Großmann K., Mykhnenko V., Rink D., 2016a. Varieties of shrinkage in European cities. European Urban and Regional Studies 23(1): 86-102. DOI 10.1177/0969776413481985.

Haase A., Rink D., Großmann K., 2016b. Shrinking cities in post-socialist Europe: What can we learn from their analysis for theory building today? Geografiska Annaler: Series B, Human Geography 98(4): 305-319. DOI 10.1111/ geob.12106.

Häussermann H., 1996. From the socialist to the capitalist city: Experiences from Germany. In Andrusz G., Harloe M., Szelenyi I. (eds), Cities after socialism: Urban and regional change and conflict in post-socialist societies. Blackwell, Oxford: 214-231. DOI 10.1002/9780470712733.ch7.

Heider B., 2019. What drives urban population growth and shrinkage in postsocialist East Germany? Growth and Change 50(4): 1460-1486. DOI 10.1111/grow.12337.

Helbig M., Jähnen S., 2018. Wie brüchig ist die soziale Architektur unserer Städte? Trends und Analysen der Segregation in 74 deutschen Städten (How fragile is the social architecture of our cities? Trends and analyses of segregation in 74 German cities). Wissenschaftszentrum Berlin für Sozialforschung, Berlin.

Helbig M., Salomo K., 2019. Sozialräumliche Spaltung in Mecklenburg-Vorpommern (Socio-spatial division in Mecklenburg-Western Pomerania). Ministerium für Energie, Infrastruktur und Digitalisierung Mecklenburg-Vorpommern, Schwerin.

Hess B.D., Tammaru T., van Ham M. (eds), 2018. Housing estates in Europe: Poverty, ethnic segregation and policy challenges. Springer International Publishing, Cham. DOI 10.1007/978-3-319-92813-5.

Hochstenbach C., Mustard S., 2018. Gentrification and the suburbanization of poverty: Changing urban geographies through boom and bust periods. Urban Geography 39(1): 26-53. DOI 10.1080/02723638.2016.1276718.

Hoekstra M.S., Hochstenbach C., Bontje M.A., Musterd S., 2020. Shrinkage and housing inequality: Policy responses to population decline and class change. Journal of Urban Affairs 42(3): 333-350. DOI 10.1080/07352166.2018.1457407.

Kneebone E., Nadeau C.A., 2015. The resurgence of concentrated poverty in America: Metropolitan trends in the 2000s. In: Anacker S. (ed.), The new American suburb: Poverty, race, and the economic crisis. Routledge, London: 15-38.

Kovács Z., 2020. Do market forces reduce segregation? The controversies of post-socialist urban regions of Central and Eastern Europe. In: Musterd S. (ed.), Handbook of ur- ban segregation. Edward Elgar Publishing, Cheltenham: 118-133. DOI 10.4337/9781788115605.00014.

Krieck M., 1990. Zuarin bis Schwerin: Eine Stadtchronik von 1160-1990 (Zuarin to Schwerin: A city chronicle from 1160-1990). Birkner, Hamburg.

Kuminoff N.V., Smith V.K., Timmins C., 2013. The new economics of equilibrium sorting and policy evaluation using housing markets. Journal of Economic Literature 51(4): 1007-1062. DOI 10.1257/jel.51.4.1007.

Lees L., 2008. Gentrification and social mixing: Towards an inclusive urban renaissance? Urban Studies 45(12): 24492470. DOI 10.1177/0042098008097099.

Maes M., Loopmans M., Kesteloot C., 2012. Urban shrinkage and everyday life in post-socialist cities: Living with diversity in Hrušov, Ostrava, Czech Republic. Built Environment 38(2): 229-243. DOI 10.2148/benv.38.2.229.

Maloutas T., Fujita K. (eds), 2012. Residential segregation in comparative perspective. Routledge, New York.

Marcińczak S., Musterd S., Stępniak M., 2012. Where the grass is greener: Social segregation in three major Polish cities at the beginning of the 21st century. European Urban and Regional Studies 19(4): 383-403. DOI 10.1177/0969776411428496.

Marcińczak S., Tammaru T., Novák J., Gentile M., Kovács Z., Temelová J., Valatka V., Kährik A., Szabó B., 2015. Patterns of socioeconomic segregation in the capital cities of fast-track reforming postsocialist countries. Annals of the Association of American Geographers 105(1): 183-202. DOI 10.1080/00045608.2014.968977.

Marcińczak S., Musterd S., van Ham M., Tammaru T., 2016. Inequality and rising levels of socio-economic segregation: Lessons from a pan-European comparative study. In: Tammaru T., van Ham M., Marcińczak S., Musterd S. (eds), Socio-economic segregation in European capital cities. Routledge, London: 358-382.

Martin C., Hulse K., Pawson H., 2018. The changing institutions of private rental housing: An international review. Australian Housing and Urban Research Institute, Melbourne. DOI 10.31235/osf.io/dzyrm.

Massey D., Denton N., 1988. The dimensions of residential segregation. Social Forces 67(2): 281-315. DOI $10.2307 / 2579183$.

Ohle W., Ende H., 1994. Schwerin. Seemann, Leipzig.

Petsimeris P., 1998. Urban decline and the new social and ethnic divisions in the core cities of the Italian industrial triangle. Urban Studies 35(3): 449-466. DOI $10.1080 / 0042098984853$.

Piekut A., Valentine G., 2017. Spaces of encounter and attitudes towards difference: A comparative study of two European cities. Social Science Research 62: 175-188. DOI 10.1016/j.ssresearch.2016.08.005.

Scanlon K., Whitehead C., Arrigoitia M.F. (eds), 2014. Social housing in Europe. Wiley-Blackwell, Oxford. DOI $10.1002 / 9781118412367$.

Stadt Schwerin, 2015. Integriertes Stadtentwicklungskonzept Schwerin 2025. 3. Fortschreibung (Integrated Urban Development Concept Schwerin 2025. 3rd Update). Stadt Schwerin, Schwerin.

Stadtverwaltung Schwerin, 2021. Data supplied by Fachgruppe Grundsatzangelegenheiten, Controlling, Statistik (Department of Policy Matters, Controlling, Statistics) on 22 January 2021.

Steinführer A., 2006. The urban transition of inner-city areas reconsidered: A German-Czech comparison. Moravian Geographical Reports 14(1): 3-16. 
Steinführer A., Haase A., 2007. Demographic change as a future challenge for cities in East Central Europe. Geografiska Annaler: Series B, Human Geography 89(2): 183-195. DOI 10.1111/j.1468-0467.2007.00247.x.

Stryjakiewicz T., Jaroszewska E., 2016. The process of shrinkage as a challenge to urban governance. Quaestiones Geographicae 35(2): 27-37. DOI 10.1515/quageo-2016-0013.

Sýkora L., 2009. New socio-spatial formations: Places of residential segregation and separation in Czechia. Tijdschrift voor Economische en Sociale Geografie 100(4): 417-435. DOI 10.1111/j.1467-9663.2009.00550.x.

Turok I., Mykhnenko V., 2007. The trajectories of European cities, 1960-2005. Cities 24(3): 165-182. DOI 10.1016/j.cities.2007.01.007.

van Gent W., Hochstenbach C., 2020. The impact of gentrification on social and ethnic segregation. In: Musterd S. (ed.), Handbook of urban segregation. Edward Elgar Publishing, Cheltenham: 358-382. DOI 10.4337/9781788115605.00026.

van Ham M., Tammaru T., Ubarevičienè R., Janssen H. (eds), 2021. Urban socio-economic segregation and income inequali- ty: A global perspective. Springer International Publishing, Cham. DOI 10.1007/978-3-030-64569-4.

van Leeuwen E.S., Vega S.H., 2021. Voting and the rise of populism: Spatial perspectives and applications across Europe. Regional Science Policy \& Practice 13(2): 209-219. DOI 10.1111/rsp3.12411.

Valatka V., Burneika D., Ubarevičienė R., 2016. Large social inequalities and low levels of socio-economic segregation in Vilnius. In: Tammaru T., van Ham M., Marcińczak S., Musterd S. (eds), Socio-economic segregation in European capital cities. Routledge, London: 313-332.

Vogel B., 2020. Schrumpfende Regionen: Ein ostdeutsches Schicksal? (Shrinking regions: An East German fate?). Bundeszentrale für politische Bildung. Online: bpb. de/geschichte/deutsche-einheit/lange-wege-derdeutschen-einheit/47550/schrumpfende-regionen (accessed: 21 July 2021).

Wolff M., Wiechmann T., 2018. Urban growth and decline: Europe's shrinking cities in a comparative perspective 1990-2010. European Urban and Regional Studies 25(2): 122-139. DOI 10.1177/0969776417694680. 